Technological University Dublin

DƯBLIN

ARROW@TU Dublin

\title{
Correlation between the structure and the anticorrosion barrier properties of hybrid sol-gel coatings: application to the protection of AA2024-T3 alloys
}

\author{
Maikki Cullen \\ Technological University Dublin \\ Muhammad Morshed \\ Technological University Dublin \\ Mary O'Sullivan \\ Technological University Dublin
}

See next page for additional authors

Follow this and additional works at: https://arrow.tudublin.ie/cenresart

Part of the Medicinal-Pharmaceutical Chemistry Commons

\section{Recommended Citation}

Cullen, M., Morshed, M. \& O'Sullivan, M. (2017). Correlation between the structure and the anticorrosion barrier properties of hybrid sol-gel coatings: application to the protection o fAA2024-T3 alloys. Journal of Sol-Gel Science and Technology, vol. 82, no. 3, pg. 801-816. 10.1007/s10971-017-4349-4

This Article is brought to you for free and open access by the Crest: Centre for Research in Engineering Surface Technology at ARROW@TU Dublin. It has been accepted for inclusion in Articles by an authorized administrator of ARROW@TU Dublin. For more information, please contact arrow.admin@tudublin.ie, aisling.coyne@tudublin.ie,gerard.connolly@tudublin.ie.

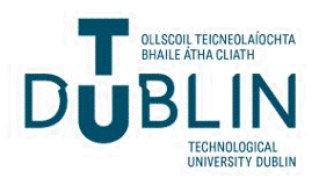




\section{Authors}

Maikki Cullen, Muhammad Morshed, Mary O'Sullivan, Emma McHugh, Brendan Duffy, and Mohamed Oubaha 


\title{
Correlation between the structure and the anticorrosion barrier properties of hybrid sol-gel coatings: application to the protection of AA2024-T3 alloys
}

\author{
Maikki Cullen ${ }^{1,2} \cdot$ Muhammad Morshed $^{2} \cdot$ Mary O'Sullivan $^{2} \cdot$ Emma MacHugh $^{1,2}$ • \\ Brendan Duffy ${ }^{2} \cdot$ Mohamed Oubaha ${ }^{2}$
}

Received: 27 August 2016 / Accepted: 27 February 2017

(C) Springer Science+Business Media New York 2017

\begin{abstract}
Hybrid sol-gel materials have been extensively studied as viable alternatives to toxic chromate (VI)-based coatings for the corrosion protection of AA2024-T3 in the aerospace industry, due to the wide range of available chemistries they offer and the tremendous development potential of innovative functional coatings. However, so far, little work has been performed in identifying the effect of the employed chemistries on the structure and anticorrosion properties of the coatings. This work proposes to contribute to a better understanding of the relationship existing between the structure, morphology and anticorrosion properties of hybrid sol-gel coatings deposited on AA2024T3 aluminium surfaces, the most widely used alloy in the aerospace industry. The sol-gels are prepared employing two hybrid precursors; an organosilane, 3-trimethoxysilylpropylmethacrylate, and a zirconium complex prepared from the chelation of zirconium $n$-propoxide, and methacrylic acid. The structure of the hybrid sol-gel formulation is modified by altering the concentration of the transition metal complex. The structure and morphology of the coatings are characterised by dynamic light scattering, fourier transform infrared spectroscopy, silicon nuclear magnetic resonance spectroscopy, differential scanning calorimetry, scanning electron microscopy, atomic-force microscopy and the anticorrosion barrier properties characterised by electrochemical impedance spectroscopy and
\end{abstract}

Mohamed Oubaha

mohamed.oubaha@dit.ie

1 School of Chemical and Pharmaceutical Sciences, Dublin Institute of Technology, Kevin Street, Dublin 8, Ireland

2 Centre for Research in Engineering Surface Technology (CREST), FOCAS Institute, Dublin Institute of Technology, 13 Camden Row, Dublin 8, Ireland neutral salt-spray. It is found that the transition metal concentration affected the morphology and structure, as well as the anticorrosion performances of the hybrid sol-gel coatings. A direct correlation between the morphology of the coatings and their final anticorrosion barrier properties is demonstrated, and the optimum material amongst this series is determined to be comprised of a concentration of between 20 and $30 \%$ of transition metal.

\section{Graphical Abstract}

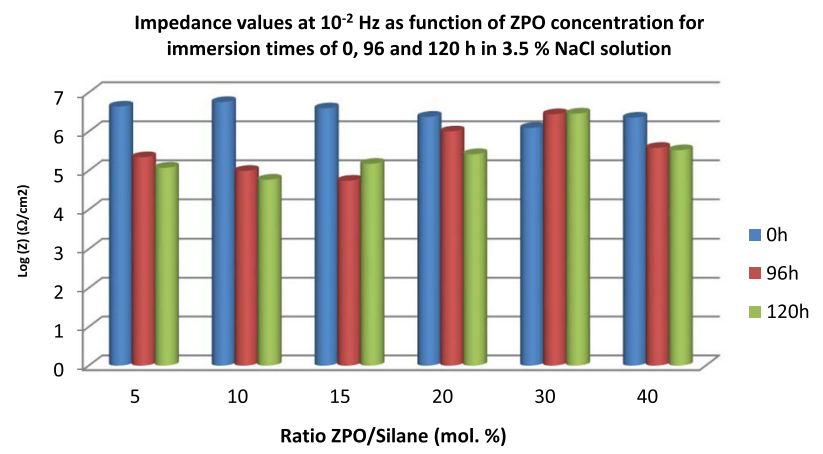

Keywords Hybrids $\cdot$ Sol-gels $\cdot$ Coatings $\cdot$ Corrosion • Structure $\cdot$ Morphology

\section{Introduction}

Many metallic substrates and their alloys are used in numerous structural applications including marine, aerospace, automotive and cultural heritage. In particular, aluminium is used extensively due to its abundance in the earth's crust $(8.1 \%)$. These metals, aluminium, iron, copper 
and magnesium are desirable due to their attractive physical characteristics such as high strength to weight ratio and stiffness; however, they are greatly susceptible to corrosion in aggressive environments. Corrosion protection of metallic substrates is therefore an active and important area of research in both industry and materials science. There are many effective anticorrosion barriers namely inorganic treatments, coatings and paints, the most popular of those being hexavalent chromium VI-based conversion coatings (CCCs). The high corrosion resistance offered by this material makes it a leading option for the protection of metallic substrates. However, due to concerns around natural environments and human health, CCCs, volatile organic compounds and hazardous air pollutants have been restricted as they are toxic and carcinogenic [1]. In order to comply with these new regulations, innovative eco-friendly protective coatings have to be developed.

One of the promising strategies proposed in the last decade is the hybrid sol-gel technology [2-4]. The interest in these materials resides in the wide range of combinations possible between the chemistries and chemical processes to achieve innovative materials with controllable morphologies and surface properties. The sol-gel process is well known with many reviews [5-7] and books available [8]. There are a wide range of precursors available but the most commonly used are organically modified silicates (ormosils), which can form functionalised nanoparticle materials via the occurrence of hydrolysis and condensation reactions.

The possibility to incorporate organic and/or inorganic species within the silicate systems has further increased the interest of the sol-gel process, in particular for the development of corrosion resistant coatings either by addition of corrosion inhibitors [9-11] or transition metals [12-14].

Of the most promising hybrid systems, silicate-PMMA [15-17] and silicate-epoxy [18, 19] materials have been extensively investigated with promising results being achieved for the protection of tin, steel and aluminium surfaces. However, these materials still seem to lack the self-healing ability of CCC's [20].

The sol-gel coatings prepared by transition metals and organosilane precursors are intricate systems, where the interactions between the transition metal and the silane networks can define the porosity, rigidity and adhesion to a metallic substrate. Therefore the coating performance will depend critically upon the synthesis conditions namely the precursors chosen, $\mathrm{pH}$ of catalysis, the degree of hydrolysis and the curing temperature. The investigation of these parameters is therefore essential to firstly understand the relationship existing between the preparation conditions of the materials and the structure of the coatings and also the correlation between the structure and the anticorrosion properties of the coatings. By answering these fundamental questions, optimising the design and the development of the coatings it may be possible that they will approach and possibly exceed the properties of hexavalent chromium.

This study is aimed at providing a better understanding on the effect of the structure of a hybrid sol-gel material on the morphology and passive anticorrosion properties of coatings deposited on AA2024-T3 aluminium surfaces. The sol-gels are prepared employing two hybrid precursors, an organosilane, 3-trimethoxysilylpropylmethacrylate, and a zirconium complex prepared form the chelation of zirconium $n$-propoxide and methacrylic acid. The structures of the hybrid sol-gel formulations are modified by altering only the concentration of the transition metal complex, while ensuring that all other preparation conditions are identical. The developed materials are characterised by dynamic light scattering (DLS), fourier transform infrared spectroscopy (FTIR), silicon nuclear magnetic resonance spectroscopy $\left({ }^{29} \mathrm{Si}-\mathrm{NMR}\right)$, differential scanning calorimetry (DSC), scanning electron microscopy (SEM), atomic-force microscopy (AFM), cross-cut and the passive anticorrosion properties characterised by electrochemical impedance spectroscopy (EIS) and neutral salt-spray (NSS).

\section{Experimental}

\subsection{Sol-gel synthesis}

The synthesis of the sol-gel matrix is based on the formation of a stable and homogeneous sol obtained from the mixture of two hybrid precursors: an organically modified silicon precursor, 3-methacryloxypropyltrimethoxysilane (MAPTMS, Assay _99\% in methanol, Aldrich), and an organically modified zirconium complex, prepared from the chelation of zirconium (IV) $n$-propoxide (ZPO, Assay $70 \%$ in propanol, Aldrich) by methacrylic acid (MAAH, $\mathrm{C}_{4} \mathrm{H}_{6} \mathrm{O}_{4}$, Assay $>98 \%$, Aldrich). In this study, the molar ratio of the two hybrids has been altered in order to assess its influence on the structure of the sol-gels and on subsequent protective performances, as summarised in Table 1 . As both precursors are hybrids, the overall molar

Table 1 Material formulations

\begin{tabular}{lll}
\hline Sample name & Hydrolysis degree $(\%)$ & $\begin{array}{l}\text { MAPTMS/ZPO/MAAH } \\
(\mathrm{mol} \%)\end{array}$ \\
\hline Material A & 50 & $97 / 2.5 / 2.5$ \\
Material B & 50 & $95 / 5 / 5$ \\
Material C & 50 & $90 / 10 / 10$ \\
Material D & 50 & $80 / 20 / 20$ \\
Material E & 50 & $70 / 30 / 30$ \\
Material F & 50 & $60 / 40 / 40$ \\
\hline
\end{tabular}


Fig. 1 Flow chart for the preparation of hybrid sol-gels

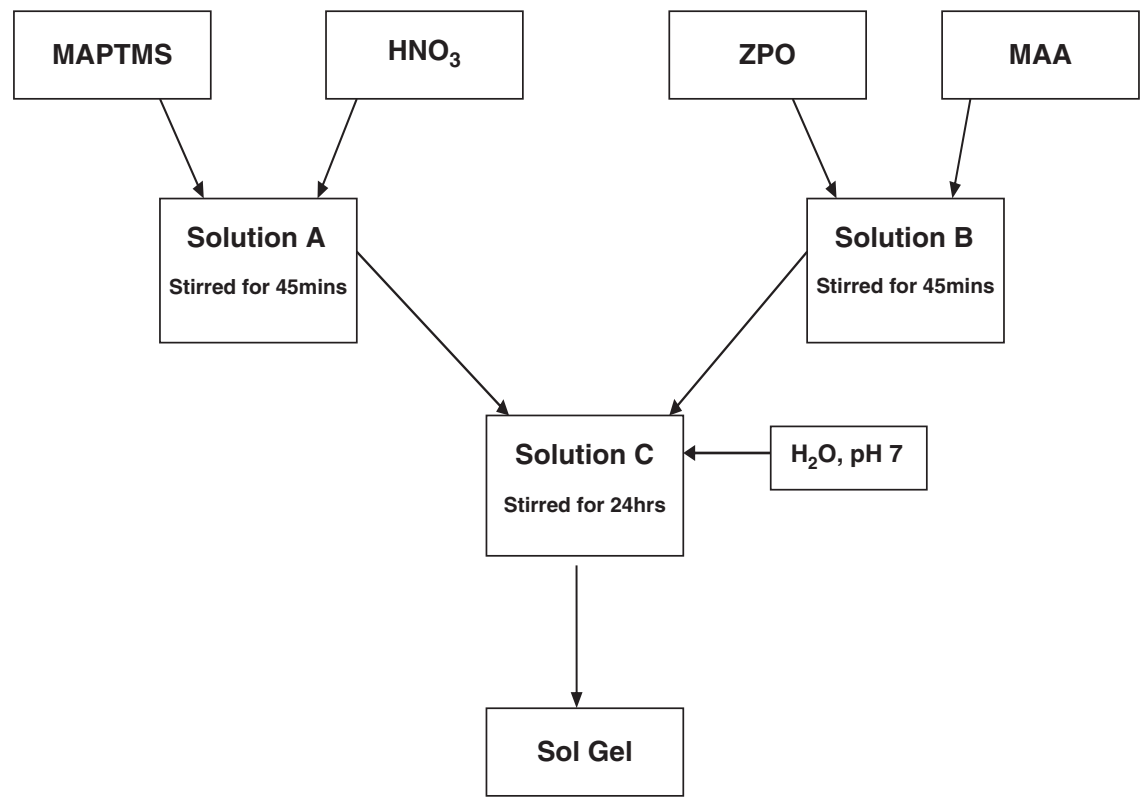

concentration of inorganic and organic species will be identical whatever the material. However, the nature of the inorganic and organic species are altered, i.e. the increase of the hybrid zirconium involving the decrease of the hybrid silane species.

As shown in Fig. 1, due to the difference in reactivity of each alkoxide precursor present in the sols, the synthesis demands a three-step process: (1) pre-hydrolysis of the MAPTMS and complexation of ZPO with a chelating agent, (2) addition of the pre-hydrolysed alkoxysilane within the zirconate complex and (3) hydrolysis of the mixture. MAPTMS is hydrolysed employing an aqueous $\mathrm{HNO}_{3} 0.1$ $\mathrm{N}$ solution with a 1:0.75 ratio. MAPTMS being immiscible with water, the hydrolysis is performed in a heterogeneous way for about $5 \mathrm{~min}$ until the production of methanol becomes sufficient to enable miscibility of all species in solution. In parallel, as transition metal alkoxides are well known to react violently with water based solutions, ZPO is chelated using MAAH to block two of its alkoxide groups and minimise precipitation when in contact with water. Both reactions are performed simultaneously and allowed to run for $45 \mathrm{~min}$. Then, the partially hydrolysed MAPTMS was slowly added to the zirconate complex. Following, 5 min of reaction, a neutral hydrolysis is performed employing deionised water, which was added dropwise to the mixture. This second hydrolysis is performed in neutral conditions to avoid further addition of pollutants, such as nitrates (as used in the first hydrolysis) while achieving a $50 \%$ hydrolysis degree. A more detailed account of the sol-gel synthesis can be found in a previous paper by the authors [21].

\subsection{Preparation of sol-gel coatings}

AA2024-T3 aluminium panels $(150 \times 100 \mathrm{~mm})$ were sourced from Amari (Irl.) Ltd., Clondalkin, Ireland. The panels were first degreased with isopropanol and subsequently etched using a hydrofluoric acid aqueous solution (Novaclean 104, Henkel, Irl.) and a sulphuric acid aqueous solution (Novox 302, Henkel, Irl.). This final acid rinsing step enabled the surface activation by creation of hydroxyl groups. The sols were filtered using a $0.45 \mu$ syringe filter and deposited employing a spin-coater at $1000 \mathrm{rpm}$ under an alcohol saturated environment. The coatings fabrications were performed in a cleanroom environment to avoid particle contamination. The fabricated coatings showed thicknesses of $4.5-5 \mu$, as determined using a non-ferrous thickness probe, an Elcometer 256. The purpose of spincoating in an alcohol saturated environment is to control the kinetic of evaporation of the solvents during the deposition process, thus obtaining high quality and homogeneous thin films, as previously described in another study by the authors [22]. For this purpose, the spin-coater was adapted to receive alcohol saturated nitrogen $\left(\mathrm{N}_{2}\right)$, which was produced by flowing $\mathrm{N}_{2}$ through sealed flasks containing isopropanol. Also, the introduction of $\mathrm{N}_{2}$ into the spin-coater significantly reduces the levels of atmospheric humidity present during spin-coating (relative humidity is typically reduced to $<5 \%$ ), thus inhibiting the formation of a surface gel layer during spinning by rapid hydrolysis and condensation reactions on the surface. The coatings are then cured for $1 \mathrm{~h}$ at $120^{\circ} \mathrm{C}$ to enable full stabilisation. The curing temperature of $120^{\circ} \mathrm{C}$ was chosen to ensure that the 
effect of the condensation was focused solely on condensation resulting from chemical and not thermal means e.g., as a result of heat curing. All finishes were touch-dry with a gloss finish. Importantly, it is found that this process facilitates the fabrication of highly homogeneous and residue free coatings, a critical point for the accurate correlation of the coating structure on the morphology and anticorrosion properties that are the core focus of this study.

\subsection{Dynamic light scattering (DLS)}

Sol-gel particle sizes were determined using a Malvern Nano-ZS instrument, using the DLS technique. The technique is a well-established optical method used to study dynamic processes of liquids and solids. The experiment was conducted at an ambient temperature.

\subsection{Fourier transform infrared spectroscopy (FTIR)}

FTIR spectroscopy is employed to identify the vibrational modes of the different chemical groups present in the sol-gels. More specifically for the current study, it is expected to shed light on the possible differences in terms of degree of condensation of both the silicon and zirconiumbased groups as a function of the concentration of ZPO. FTIR spectra of all coatings were recorded employing a Perkin Elmer GX instrument operating in the ATR mode within the $600-4000 \mathrm{~cm}^{-1}$ spectral range.

\section{$2.5{ }^{29} \mathrm{Si}-\mathrm{NMR}$ spectroscopy}

The NMR spectra were recorded on liquid solutions at room temperature employing a $400 \mathrm{MHz}$ BRUKER spectrometer. Experimental acquisition conditions are as follows: frequency $46.69 \mathrm{MHz}$, recycle delay $4 \mathrm{~s}$, pulse $\pi / 3(8 \mu \mathrm{s})$, spectral width $500 \mathrm{ppm}$ and 80 scans. The signal chemical shift reference was tetramethylsilane and the FID (free induction decay) processing used a $10 \mathrm{~Hz}$ line broadening.

Dimethyl sulfoxide was used as the lock solvent. With these conditions, spectra with good signal-to-noise ratios were obtained.

\subsection{Differential scanning calorimetry (DSC)}

DSC is a thermal analysis technique that identifies the change of the material's heat capacity as a function of applied temperature. For this study, DSC is performed to identify the thermal behaviour of the sol-gels in order to define the optimum curing temperature to be applied as a final stabilisation treatment. DSC measurements were carried out using a Shimadzu DSC QC instrument under an air atmosphere at a heating rate of $5^{\circ} \mathrm{C} / \mathrm{min}$ between 20 and
$200{ }^{\circ} \mathrm{C}$. Samples were prepared by dropping $10 \mu \mathrm{l}$ of the liquid sol-gels into an aluminium sample pan.

\subsection{Scanning electron microscopy (SEM)}

SEM images and EDX analyses were recorded employing a Hitachi SU-70 SEM using an accelerating voltage of $5 \mathrm{keV}$ for SEM images and $20 \mathrm{keV}$ for EDX analyses. Prior to analysis, the samples were mounted by the mixture of EpoFix resin and EpoFix hardener (w/w 20:3). The mounted samples were polished using different grades of emery papers (from coarse to fine) which are P240, P500, P800 and P1200. The final polish was carried out using a diamond suspension with particles size of 9,3 and $1 \mu \mathrm{m}$. The polishing process was carried out by using a Motopol $^{\mathrm{Tm}}$ 2000 grinder/polisher. The polished samples were coated with approximately $4 \mathrm{~nm}$ of platinium/palladium coating using a Cressington 208HR sputter coater to make the sample conductive, and to minimise charging during image recording.

\subsection{Atomic force microscopy (AFM)}

A scanning AFM (Pacific Nanotechnology: Nano-RTM) was used to characterise the surface topography and roughness of the coatings. At least three measurements were taken of the same scan size of $85 \times 85 \mu \mathrm{m}$ from three different areas of the sample surface. The root-mean-square roughness was measured and the average value of the surface roughness calculated.

\subsection{Electrochemical impedance spectroscopy (EIS)}

EIS data were recorded using a Solartron SI 1287/1255B system comprising a frequency analyser and a potentiostat. All scans were acquired in the region from -0.4 to $+0.5 \mathrm{~V}$ vs. Eoc, with a scan rate of $20 \mathrm{mV} / \mathrm{s}$ at room temperatures $\left(20 \pm 2{ }^{\circ} \mathrm{C}\right)$. Electrochemical impedance data was performed using the electrochemical cells prepared by slicing polypropylene sample bottles $(2.5 \mathrm{~cm}$ diameter $) 10 \mathrm{~mm}$ from the base, which were then secured on the sol-gel coated aluminium substrate using a $2 \mathrm{~K}$ epoxy adhesive (Araldite, Radionics (Ireland)). A dilute Harrison's solution was used as electrolyte $\left(0.35 \mathrm{wt} . \%\left(\mathrm{NH}_{4}\right)_{2} \mathrm{SO}_{4}\right.$ and 0.05 wt.\% $\mathrm{NaCl}$ ). All measurements were made at the open circuit potential (OCP, Eoc) with an applied $10 \mathrm{mV}$ sinusoidal perturbation in the frequency range $1 \times 10^{5}-1 \times 10^{-2} \mathrm{~Hz}$ (10 points per decade).

\subsection{Neutral salt spray exposure (NSS)}

NSS tests were conducted according to ISO 9227, the required aerospace standard for corrosion characterisation. 
According to this standard, the samples are exposed to a neutral salt fog atmosphere generated from $5 \mathrm{wt} \% \mathrm{NaCl}$ solution at $35^{\circ} \mathrm{C}( \pm 1)$. The back and sides of each panel are protected with insulating tape. The aerospace standard test duration is $500 \mathrm{~h}$.

\subsection{Coatings adhesion}

Coatings were assessed for their surface adhesion by means of cross-cut test according to PN-EN ISO 2409. The coatings were incised into the substrate with a multi-cut tool equipped cutters with the spacing of $1 \mathrm{~mm}$. The surface of incision network was examined employing an optical microscope and classified on 0-5 six-point scale. According to the PN-EN ISO 2409 standard, surface adhesion showing smooth sand sharp cuttings with no delamination are classified with 0 score, while the most damaged coatings with a delamination exceeding $65 \%$ of the surface are classified with a 5 score.

\section{Results and discussion}

\subsection{Particle size analysis}

Particle sizes for all materials recorded $24 \mathrm{~h}$ after the synthesis are represented in Fig. 2. It can be seen that all spectra exhibit a single band, ranging from 1.5 to $18 \mathrm{~nm}$, the main differences being in the position and the full width at half maximum (FWHM) of the bands. These characteristics provide information of the materials size and homogeneity, and indicate the condensation capacity of the materials. In order to better appreciate the evolution of these characteristics, the FWHM and maximum peak position of the materials have been represented in Fig. 3. It can be seen that for materials $\mathrm{A}-\mathrm{C}$, the size of the nanoparticles ranges between 3 and $3.6 \mathrm{~nm}$ and range within the error bar. However, for materials D-F, the nanoparticle size ranges between 5 and $6.5 \mathrm{~nm}$ with a clear linear growth with the increase of the zirconium complex concentration. The
Fig. 2 DLS spectra for sol-gel A-F
Fig. 3 Representation of the FWHM and peak position for materials $\mathrm{A}-\mathrm{F}$
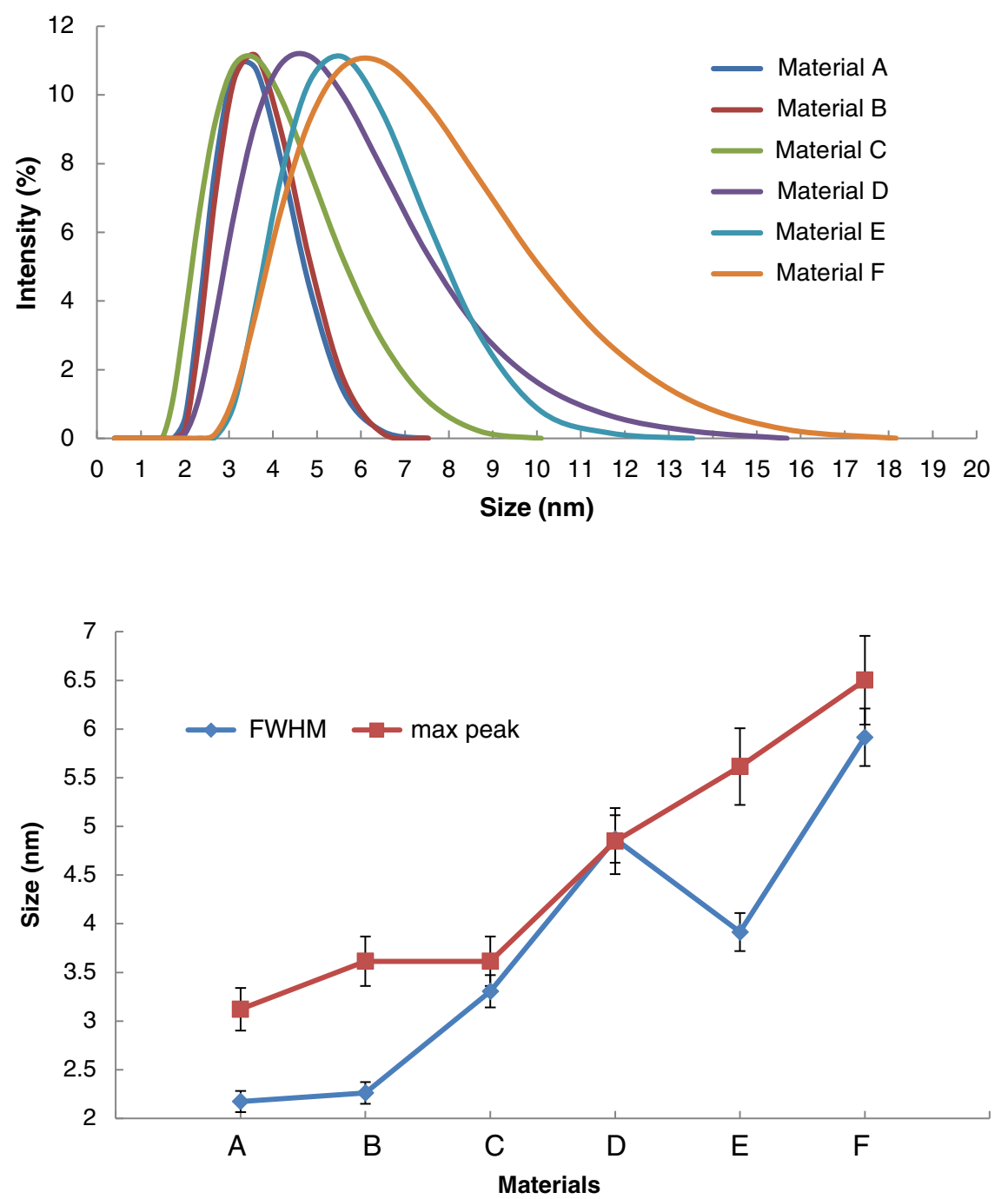
FWHM is seen to progressively increase as the concentration of the zirconium complex increases, with the exception of material E, where a lower FWHM when compared to material D is observed. These results indicate that the more homogenous material systems are obtained when the zirconium complex concentration does not exceed 5\%. The explanation to these phenomena can only be found by identifying the role of the zirconium complex within the organosilane matrix. In a previous study performed by the authors [10], in similar materials, the zirconium atom has been found to act as a catalyst of the condensation of the silanol groups formed during the hydrolysis of MAPTMS, while also participating to the formation of the inorganic backbone. Therefore, the most plausible explanation to the differences observed in peaks and FWHM here would be in relation to the ability of the zirconium complex to be incorporated in an existing backbone without affecting the overall structure of the nanoparticles or to actively crosslink particles of different sizes. Taking this hypothesis into account, it is clear that when the zirconium is added in concentrations not greater than $5 \%$, it is likely to be incorporated within the organosilane matrix. Therefore, its role here would be as a densifier of the organosilane nanoparticles. For material C, nanoparticle populations of sizes of up to $9 \mathrm{~nm}$ can be observed, which can be explained by the aggregation of nanoparticles observed in materials with a lower concentration of zirconium. This means that for a concentration of $10 \%$ of zirconium complex, the transition metal starts to act as a crosslinker. This is further confirmed by the spectra of materials D, E and F, where nanoparticles populations of up to 10,12 and $16 \mathrm{~nm}$ are observed, respectively. Owing to these results, from a physico-chemistry point of view, it is very likely that the transition metal can be loaded within the organosilane matrix for concentrations of up to $5 \%$. From $10 \%$, the incorporation of zirconium within the silane matrix is still taking place; however, some of it remains at the surface of the nanoparticles, explaining the partial crosslinking activity. For concentrations greater than $10 \%$, it is clear that the zirconium complex acts as crosslinking system, of multiple nanoparticles, as those formed in materials A, B, and C. Consequently, the DLS results highlight the role of the zirconium complex in the polycondensation process. However, this technique is insufficient to provide information on the structural evolution of the materials, which will be performed by FTIR spectroscopy in the following section.

\subsection{FTIR analysis}

Figure 4a shows the FTIR spectra of all prepared coatings. All absorption bands were ascribed based on results reported in closely related materials [23-25]. All spectra show the presence of the same chemical vibrations due to the employment of the same precursors and materials preparation, the difference being essentially in the ratio of the precursors.

The broad band located in the range $800-1200 \mathrm{~cm}^{-1}$ is characteristic of the silicate network resulting mainly from the superimposition of the silanol ( $\mathrm{Si}-\mathrm{OH}, 890 \mathrm{~cm}^{-1}$ ) stretches, $\mathrm{Si}-\mathrm{O}-\mathrm{Si}\left(840\right.$ and $\left.1010-1050 \mathrm{~cm}^{-1}\right)$ and $\mathrm{Si}-\mathrm{O}-\mathrm{Zr}$ vibrations $\left(940 \mathrm{~cm}^{-1}\right)$. The band observed at $1170 \mathrm{~cm}^{-1}$ symbolises the stretching of the $\mathrm{Si}-\mathrm{O}-\mathrm{C}$ contained in the methoxy-silane groups of the MAPTMS. The $\mathrm{Zr}-\mathrm{OH}$ and $\mathrm{Zr}-\mathrm{O}-\mathrm{C}$ bonds composing the zirconium complex are located in the region $1300-1650 \mathrm{~cm}^{-1}$. The $\mathrm{Zr}-\mathrm{MAAH}$ complex possesses two peaks around 1635 and $1533 \mathrm{~cm}^{-1}$, which are ascribable to the symmetric $\left(\nu_{\mathrm{s}}\right)$ and asymmetric stretching $\left(\nu_{\text {as }}\right)$ vibrations of the carboxylic group $\left(\mathrm{COO}^{-}\right)$, respectively [26]. With a $\Delta \mathrm{v}\left(\mathrm{COO}^{-}\right)$value of $102 \mathrm{~cm}^{-1}$, the chelate can be said to be bidentate. The bands located at $1730,2800,3000$ and $3200 \mathrm{~cm}^{-1}$ are due to the $\mathrm{C}-\mathrm{O}$ (stretching), $\mathrm{C}-\mathrm{H}$ (stretching) and residual $\mathrm{Si}-\mathrm{OH}$ and $\mathrm{Zr}-\mathrm{OH}$ groups (stretching), respectively. However, to more precisely identify the effect of the formulations on the possible reactivity and condensation of the materials, one needs to focus on the characteristic vibration bands of the inorganic backbone, namely the silicon and zirconium oxide related moieties. As shown in Fig. 4b, the typical vibration of the siloxane bands located at $840 \mathrm{~cm}^{-1}$ and in the range $1010-1040 \mathrm{~cm}^{-1}$ can be observed in all samples demonstrating the occurrence of the sol-gel condensation reactions of the ormosil. However, it can be observed that the band located $940 \mathrm{~cm}^{-1}$ symbolising the presence of the $\mathrm{Si}-\mathrm{O}-\mathrm{Zr}$ groups is progressively increasing as the concentration of the zirconium complex increases. It can also be noted that this band cannot be seen in material $\mathrm{A}$, and its relative presence against the band at $1040 \mathrm{~cm}^{-1}$ increases to become similar in intensities in material $\mathrm{E}$. This demonstrates that the insertion of the zirconium complex within the silicate network takes place and indicates the formation of a uniform co-hybrid system, as suggested by the DLS results, where a single nanoparticle system was detected.

\section{$3.3{ }^{29}$ Si-NMR analysis}

${ }^{29} \mathrm{Si}$-NMR spectra of all samples recorded at the end of the synthesis are presented in Fig. 5. Knowing that the ${ }^{29} \mathrm{Si}$ NMR spectra of the pure MAPTMS exhibits a single sharp peak at $-42.7 \mathrm{ppm}$ (not shown here), the presence of different chemical shifts in the $T_{0}, T_{1}, T_{2}$, and $T_{3}$ regions clearly translate the occurrence of condensation reactions of the methoxysilane groups of the MATPMS. In order to better quantify the concentration of the different formed $\mathrm{T}$ species for each materials, the signals of each species were integrated and their relative proportions plotted in Fig. 6. It 
Fig. 4 FTIR spectra for coatings $\mathrm{A}-\mathrm{F}$ a in the range $600-4000 \mathrm{~cm}^{-1}$ and $\mathbf{b}$ in the range $800-1200 \mathrm{~cm}^{-1}$ (a)

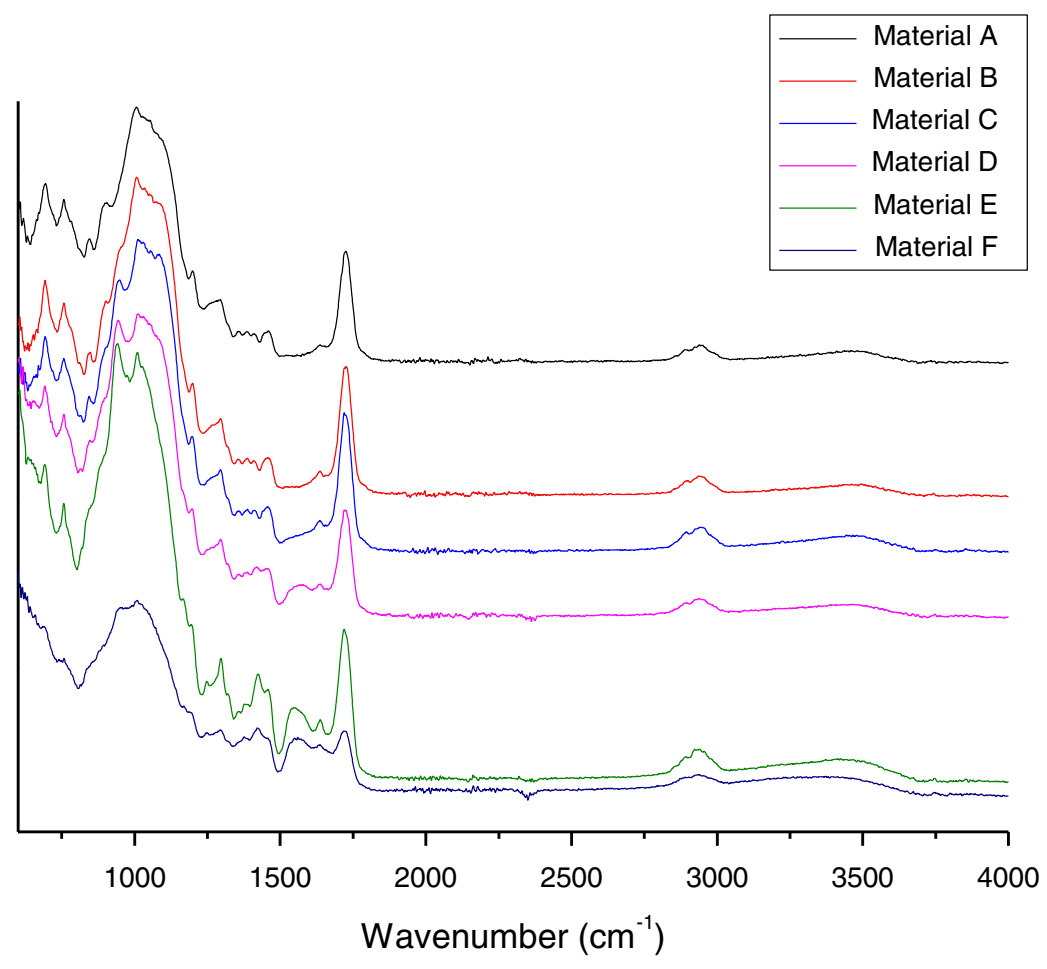

(b)

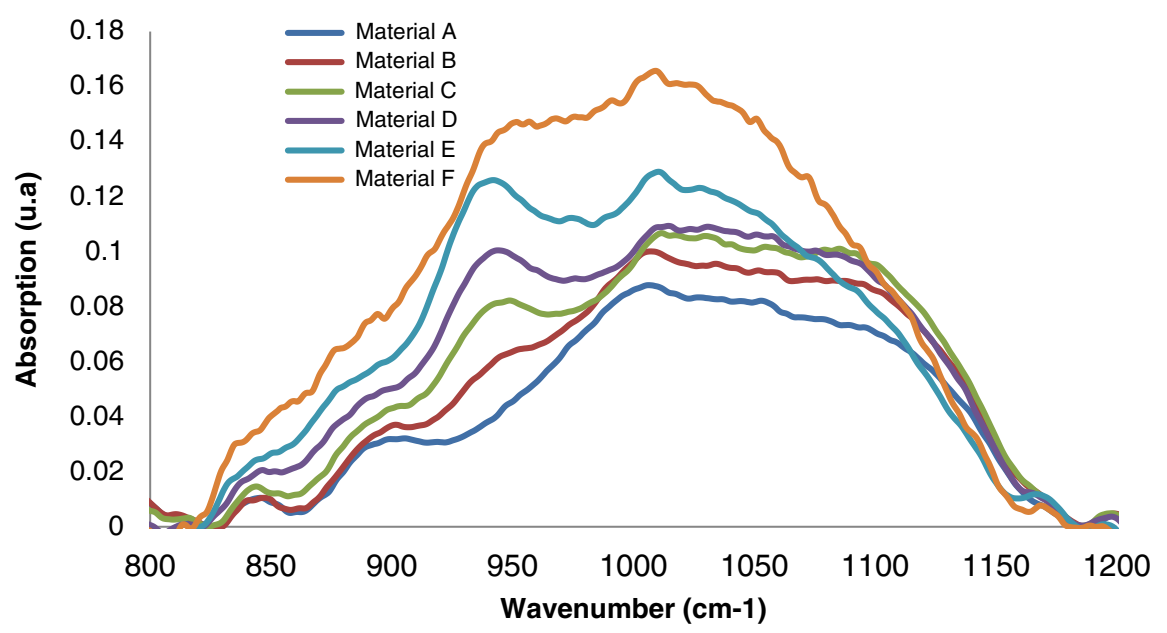

can be seen that $T_{0}$ groups are absent in materials B and C and are present in materials $\mathrm{A}, \mathrm{D}, \mathrm{E}$ and $\mathrm{F}$ with proportions of $5,3,16$ and $32 \%$, respectively. $T_{1}$ groups are detected in all materials with concentration of 33, 36, 34, 41, 51 and $49 \%$, from material A to $\mathrm{F}$, respectively. $T_{2}$ groups are seen with relative proportions of $43,48,50,45,30$ and $19 \%$, from materials A to $\mathrm{F}$, respectively. $T_{3}$ groups are detected with relative proportions of $18,14,15,10,3$ and $0 \%$, from material A to F, respectively. These results would suggest that the content of $T_{3}$ groups, which are the most condensed species, dramatically decrease for concentrations of ZPO greater than $10 \%$, with none detected for material $\mathrm{F}$. In parallel, $T_{1}$ groups that are found in similar contents in materials $\mathrm{A}-\mathrm{C}$, undergo a regular increase from material $\mathrm{D}$, with a quasi-stagnation observed in materials $\mathrm{E}$ and $\mathrm{F}$. However, $T_{0}$ groups which are absent in material $\mathrm{B}$ and $\mathrm{C}$, and present in a low content in material A, are constantly increasing from material $\mathrm{D}$ to reach their maximum in material $\mathrm{F}$. Therefore, the materials forming the most condensed silicate systems are materials B and C. Materials A and D would have similar condensed silicate networks, while materials $\mathrm{E}$ and $\mathrm{F}$ would exhibit the minimum condensed silicate network. The explanation to this behaviour is likely to rely on the steric hindrance imposed by the zirconium atom to the silicate network. Indeed, the formation of highly condensed species at low concentration of 


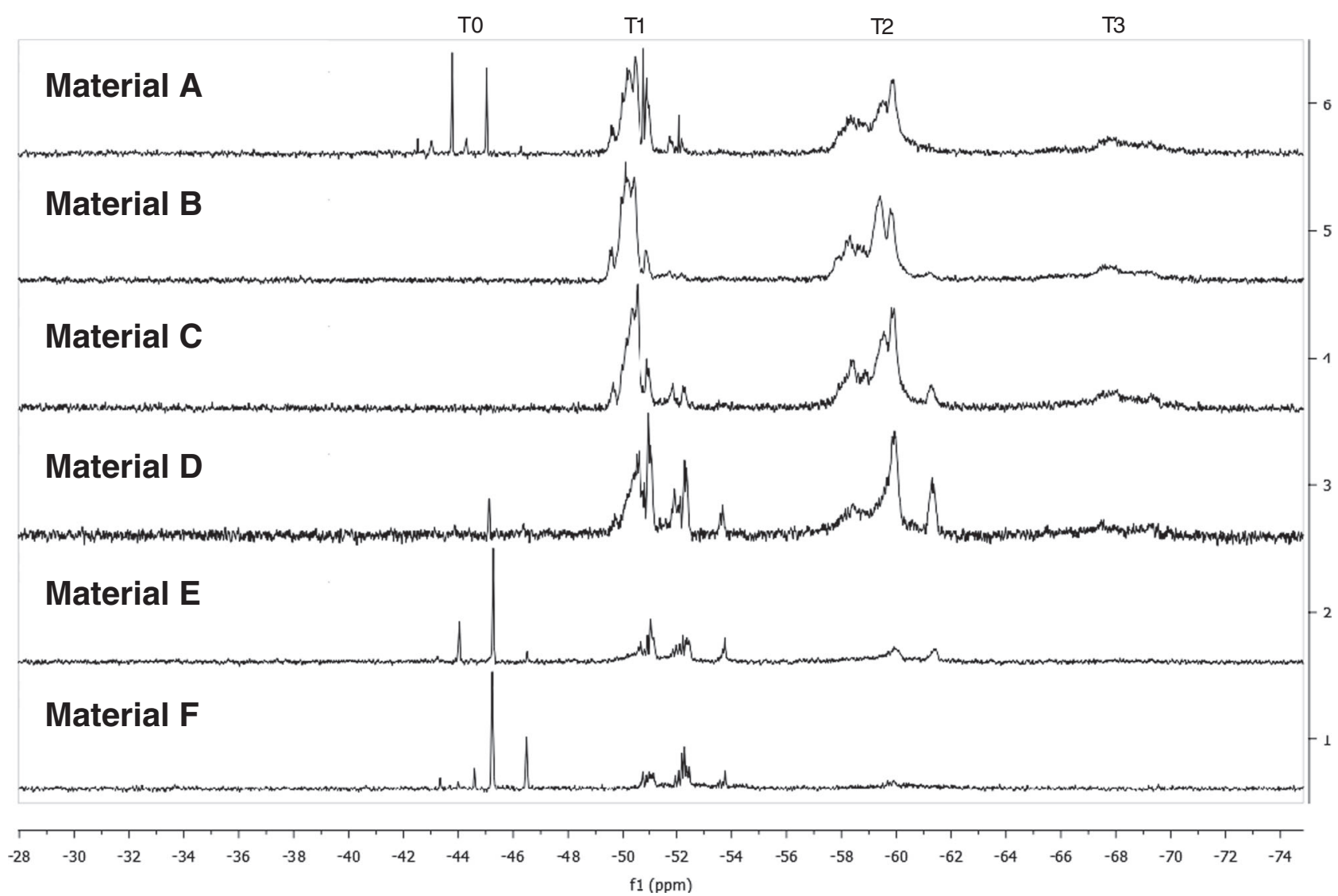

Fig. $5{ }^{29}$ Si-NMR spectra of materials A-F. $T_{0}, T_{1}, T_{2}$ and $T_{3}$ groups are observed in the ranges -40 to $47,-48$ to $54,-57$ to 62 and -66 to 72 ppm, respectively

ZPO would suggest that the hybrid silicate system can easily auto-condense, similarly to non-transition-metal silicate sol-gel materials, as previously reported [27-29]. It is possible that up to $10 \% \mathrm{ZPO}$, the porosity of the silicate nanoparticles is filled by the ZPO without dramatically altering the reactivity of the silicate species. However, for materials $\mathrm{D}, \mathrm{E}$ and $\mathrm{F}$, the progressive incorporation of $\mathrm{ZPO}$ within the silicate network tends to reduce the interaction of the different silicate groups and would more preferably favour the formation of $T_{1}$ groups with the zirconium atom. In addition, again for steric hindrance reasons, the formation of multiple chemical bonds between the silicon and zirconium atom is unlikely, thus explaining the low content of the $T_{2}$ and $T_{3}$ groups and the high content of $T_{0}$ and $T_{1}$ groups in materials E and F. In summary, these NMR results have highlighted that the condensation of the silicate species are dramatically affected by the ZPO concentration.

\subsection{Thermal analysis}

Thermal analysis was performed by DSC to identify the possible effect of the materials composition on the thermal

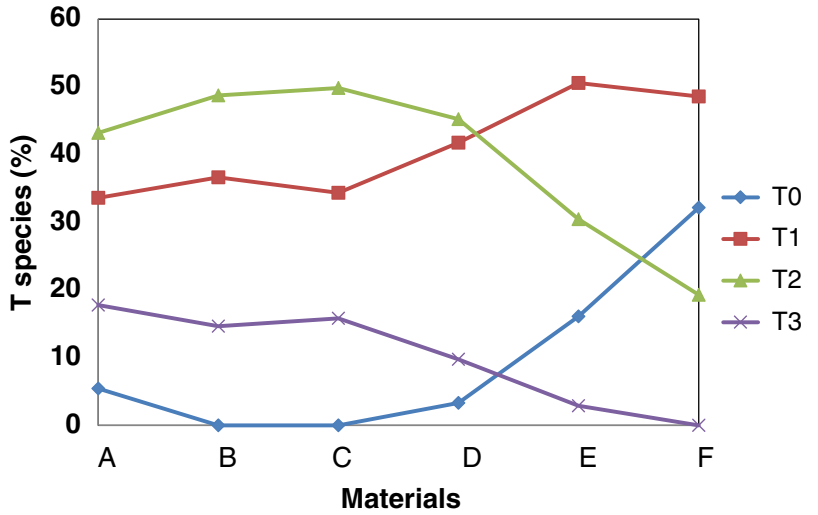

Fig. 6 Evolution of the concentration of $T_{0}, T_{1}, T_{2}$ and $T_{3}$ species for materials A-F, as calculated from ${ }^{29} \mathrm{Si}-\mathrm{NMR}$ spectra shown in Fig. 5

behaviour of the sol-gels and to identify the glass transition temperatures. As the aim of our study is to determine only the chemical effects on the condensation of the materials and minimise the role of the curing densification, the curing temperature needs to be below the $\mathrm{Tg}$ and as low as 
Fig. 7 DSC analyses for materials $\mathrm{A}$ to $\mathrm{F}$

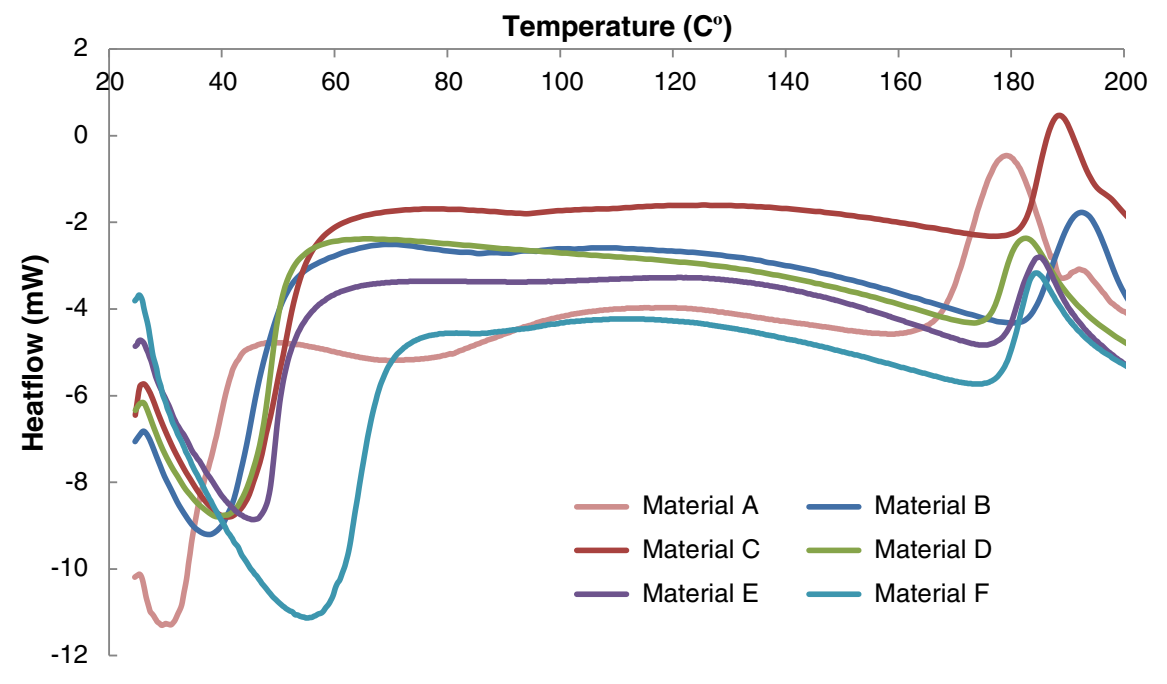

possible. DSC analysis was performed on liquid sol-gel materials between room temperature and $200{ }^{\circ} \mathrm{C}$, although the working temperature for a typical hybrid coating would be likely to be below $150{ }^{\circ} \mathrm{C}$. Figure 7 shows the DSC spectra recorded for all prepared samples. In these spectra, three different thermal zones can be identified namely, below $100^{\circ} \mathrm{C}$, between 100 and $150{ }^{\circ} \mathrm{C}$ and above $150^{\circ} \mathrm{C}$, where typically the evaporation of the solvents, condensation reactions and glass transition take place, respectively. For all samples, a large endothermic band can be observed in the range $20-60^{\circ} \mathrm{C}$, suggesting the evaporation of the volatile solvents formed during the sol-gel synthesis or present in the precursors. It can be noted that this band shifts slightly as the zirconium complex concentration is increased, suggesting that more condensed structures have a higher degree of solvent entrapment. Except for material E, between typically 60 and $120^{\circ} \mathrm{C}$, it can be observed that materials $\mathrm{A}, \mathrm{B}, \mathrm{C}, \mathrm{D}$ and $\mathrm{F}$ show curves with negative slopes suggesting the occurrence of endothermic phenomena probably due to the continuation of the sol-gel condensation reactions that are catalysed by the heat provided. The absence of such behaviour in material $\mathrm{E}$ would indicate that these reactions would have taken place during the evaporation of the solvents. This clearly indicates that the transition metal has an active role in the condensation process, as demonstrated by the FTIR results. The exothermic band observed in the range of $175-200^{\circ} \mathrm{C}$ represents the glass transition temperature ( $\mathrm{Tg}$ ) of the materials and represents the full solidification of the materials. It can be seen that the $\mathrm{Tg}$ for materials $\mathrm{B}, \mathrm{C}, \mathrm{D}, \mathrm{E}$ and $\mathrm{F}$ are observed at $193,188,183,185$ and $183^{\circ} \mathrm{C}$, respectively. In this thermal range, material A exhibits two different exothermic bands located at 178 and $193{ }^{\circ} \mathrm{C}$, suggesting the presence of two different phases within the materials. Indeed, it can be proposed that for such a low concentration of zirconium, it is likely that the distribution of the transition metal within the silane matrix may result in populations of particles that are only composed of MAPTMS oligomers. Based on results obtained for materials $\mathrm{B}$ and $\mathrm{C}$, it is possible to assign the band located at $193{ }^{\circ} \mathrm{C}$ to the $\mathrm{Tg}$ of the populations containing zirconium complex, while the one observed at $178^{\circ} \mathrm{C}$ would be related to the MAPTMS oligomers. Though, the temperature difference ranges within $15^{\circ} \mathrm{C}$ for all materials, to achieve full condensation, it appears that materials $\mathrm{A}, \mathrm{B}$ and $\mathrm{C}$ require a higher temperatures than materials $\mathrm{D}, \mathrm{E}$ and $\mathrm{F}$, which range within a $2{ }^{\circ} \mathrm{C}$ temperature difference. This result further confirms that the increase of the transition metal concentration favours condensation reactions.

\subsection{SEM/EDX analyses}

Figure 8 represents a typical SEM image of a coating fabricated with these series of materials (material $\mathrm{C}$ in this case). It can be seen that the coating is uniformly deposited on the AA2024-T3 alloy with a coating thickness of $4.7 \mu$.

As shown in Fig. 9, elemental analysis of the coating was performed by EDX in order to identify the presence of the main element of the coatings namely silicon, zirconium and oxygen as well as the aluminium composition of the alloy. This technique clearly identifies the interface between the coating and the substrate, as within the coating silicon, zirconium and oxygen can be detected, whereas aluminium is found in the bottom region of the spectrum only.

\subsection{AFM analysis}

Figure 10 represents the AFM images of the coatings fabricated with the six materials. The roughness of the coatings as measured from the AFM images are plotted in Fig. 11. 
Fig. 8 SEM image of a coating prepared with material $\mathrm{C}$

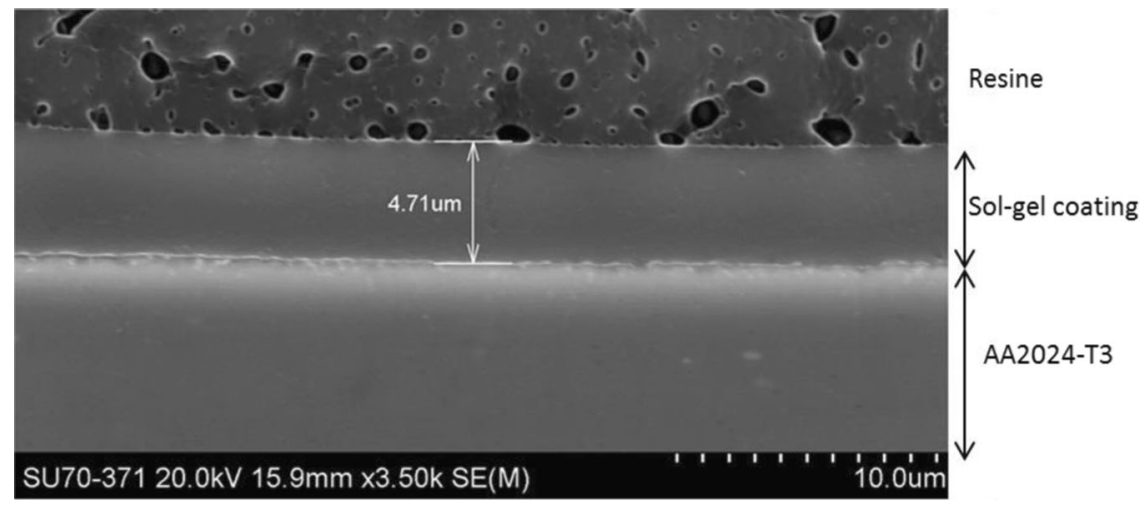

Fig. 9 EDX analysis of a coating prepared with material $\mathrm{C}$

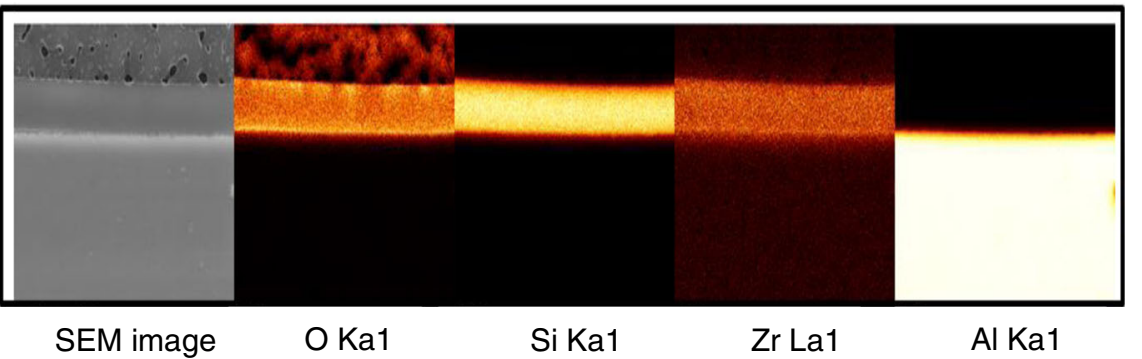

B)

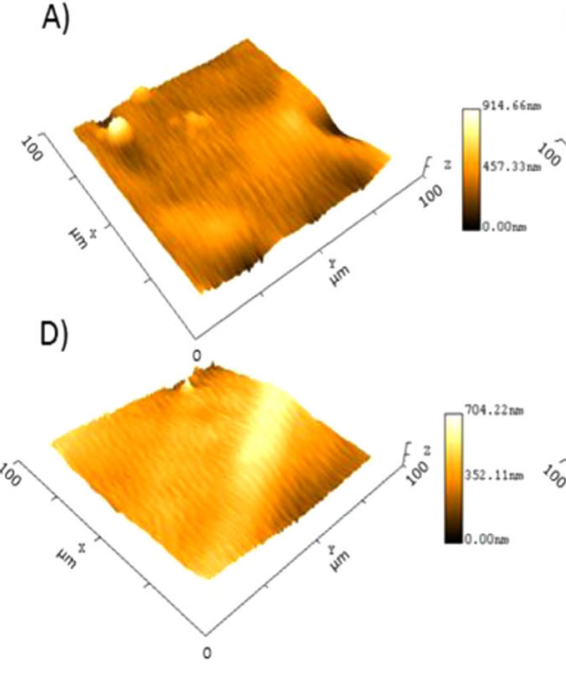

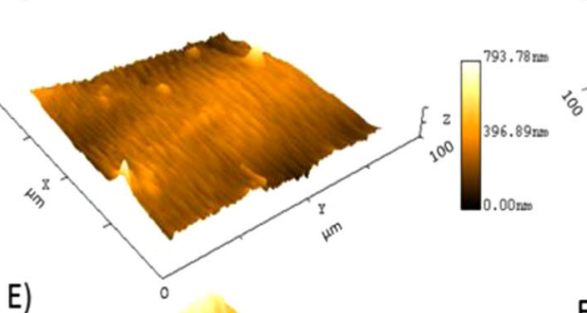

C)

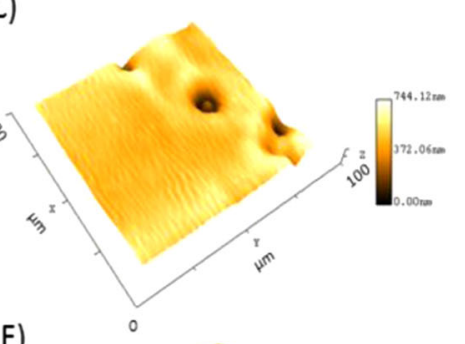

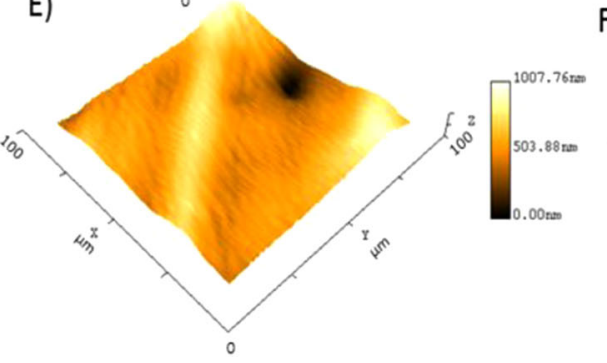

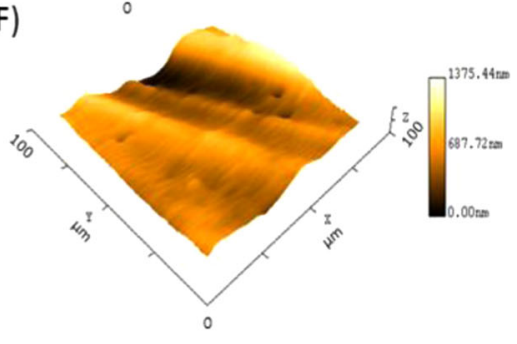

Fig. 10 AFM images of coatings prepared with materials A-F

The coating defects symbolised by black holes in coatings $\mathrm{A}, \mathrm{C}$ and $\mathrm{E}$ are probably due to impurities present on the substrates during the deposition process. It can be seen that the roughness for materials $\mathrm{A}-\mathrm{C}$ ranges between 50 and 54 $\mathrm{nm}$ and increases to $61 \mathrm{~nm}$ for materials D. However, the roughness values dramatically increase to 104 and $220 \mathrm{~nm}$ for materials $\mathrm{E}$ and $\mathrm{F}$, respectively. A possible explanation of this phenomenon could be due to varying particle sizes and their integration in the upper layer of the coatings.
As identified by the DLS analysis, the particle size is found to be quasi constant for materials $\mathrm{A}-\mathrm{C}$, whereas an increase of 55,80 and $108 \%$ is observed for materials D, E and F, respectively. Though the roughness values do not increase with the same trend as the particle sizes, it is evident that the main changes in the evolution of both properties take place from material $D$. This could be due to the fact that smaller nanoparticles can have better cohesive capabilities to form more uniform coatings, resulting in more levelled coating 
Fig. 11 Roughness values for materials $\mathrm{A}-\mathrm{F}$, as measured from AFM images

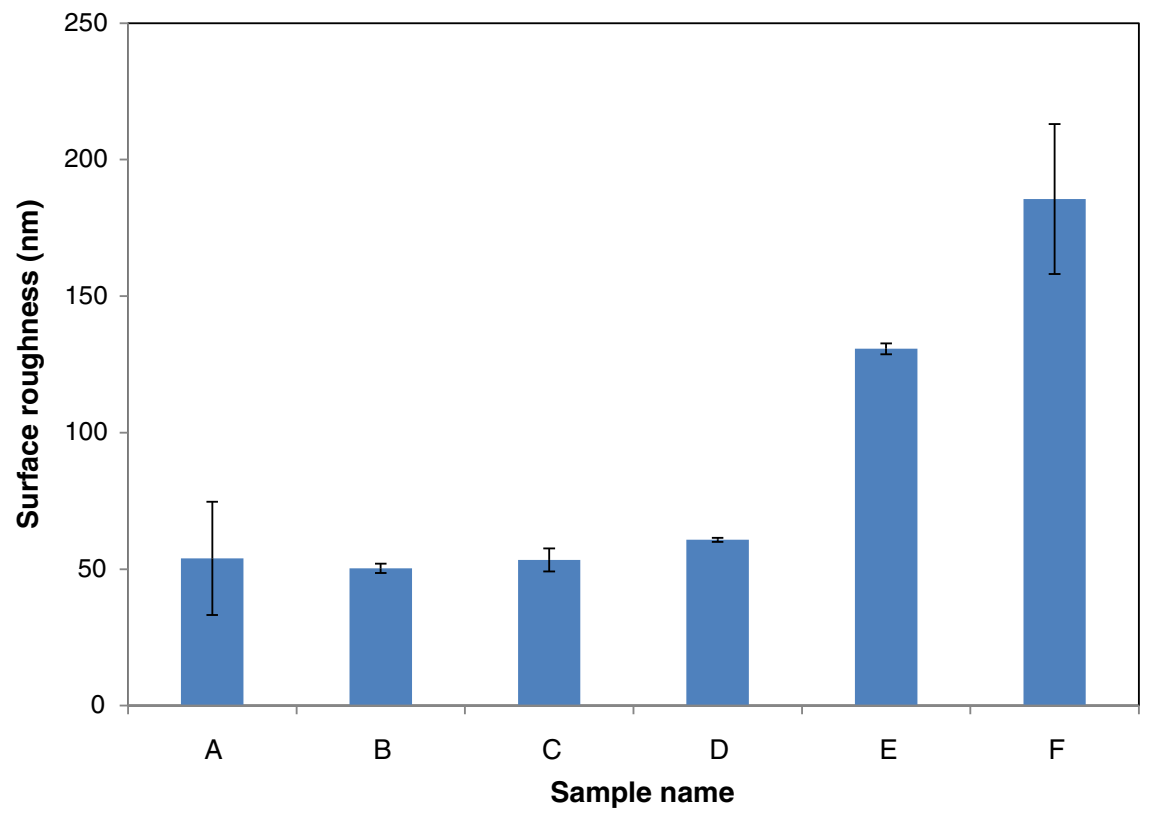

surfaces. However, conclusions on the densities of the coatings cannot be drawn from this analysis.

\subsection{Electrical impedance spectroscopy (EIS)}

EIS involves applying an AC voltage at the OCP, with a sinusoidal amplitude of varying frequency across a coating in contact with an aggressive electrolyte. The coatings' resistance to the AC signal, or impedance, varies according to the applied frequency and is graphically represented on a Bode frequency plot. The phase angle associated with the impedance gives valuable information on the film properties such as barrier performance and interfacial activity. This activity is often seen as a build-up of oxide material, usually corrosion product, which may prevent charge transfer at the metal surface thus increasing the effective interfacial capacitance. The process can be modelled as an equivalent electrical circuit as explained elsewhere [30].

The bode plot for all coatings are shown after exposure to Harrison's solution electrolyte for duration times of 0,96 and $120 \mathrm{~h}$ are represented in Fig. 12. It can be seen that for all exposure times all materials exhibit time constants at low, middle and high frequency, defined in the ranges $0-10^{-1}, 10^{-1}-10^{3}$ and above $10^{3} \mathrm{~Hz}$, respectively. All materials exhibit similarities in terms of phase differences between the initial exposure time and the $96 \mathrm{~h}$ exposure time. Except for material A, the high frequency time constant remains almost unchanged for the other materials from 96 to $120 \mathrm{~h}$ exposure times.

The time constant at low frequency, which symbolises the early penetration of water and chloride ions through the sol-gel film, is seen to decrease with exposure time and a minimum difference is observed for materials $\mathrm{B}$ and $\mathrm{E}$ for exposure times of 96 and $120 \mathrm{~h}$. The time constant at middle frequency is ascribable to the charge transfer and is seen to have disappeared for materials $\mathrm{B}$ and $\mathrm{C}$, while it remains unchanged for materials $\mathrm{E}$ and $\mathrm{F}$, and decreased for materials $\mathrm{A}$ and $\mathrm{D}$.

The impedance values at $10^{-2} \mathrm{~Hz}$ for all materials at the three different exposure times are represented in Fig. 13. It can be seen that except for material $\mathrm{E}$ the impedance values for all other materials is decreasing, when the exposure time increases. For material $\mathrm{E}$, the impedance values range within the measurement error bar at around $10^{6.3} \Omega / \mathrm{cm}^{2}$, regardless of the exposure time. This translates the capability of the coating to maintain its chemical resistance within the investigated time. From the results obtained by the EIS experiments, the most corrosion resistant coating would be obtained from material $\mathrm{E}$.

\subsection{Neutral salt spray test results (NSS)}

NSS tests are performed in agreement with the international standard ISO 9227. In order to identify the anticorrosion resistance of the different coatings, the samples were analysed after 24,48 and $144 \mathrm{~h}$ of exposure to the salt spray fog, as shown in Fig. 14. For a clearer view of the NSS results the number of pits per $\mathrm{dm}^{2}$ observed in the coatings is plotted in Fig. 15.

It can be seen that, with the exception of material $\mathrm{A}$, all other coatings showed no pits after $24 \mathrm{~h}$ of exposure. After an additional $24 \mathrm{~h}$ of exposure, the pits observed in sample A have grown along with the appearance of new pits, reaching a density of 200 pits per $\mathrm{dm}^{2}$. At the same time, 

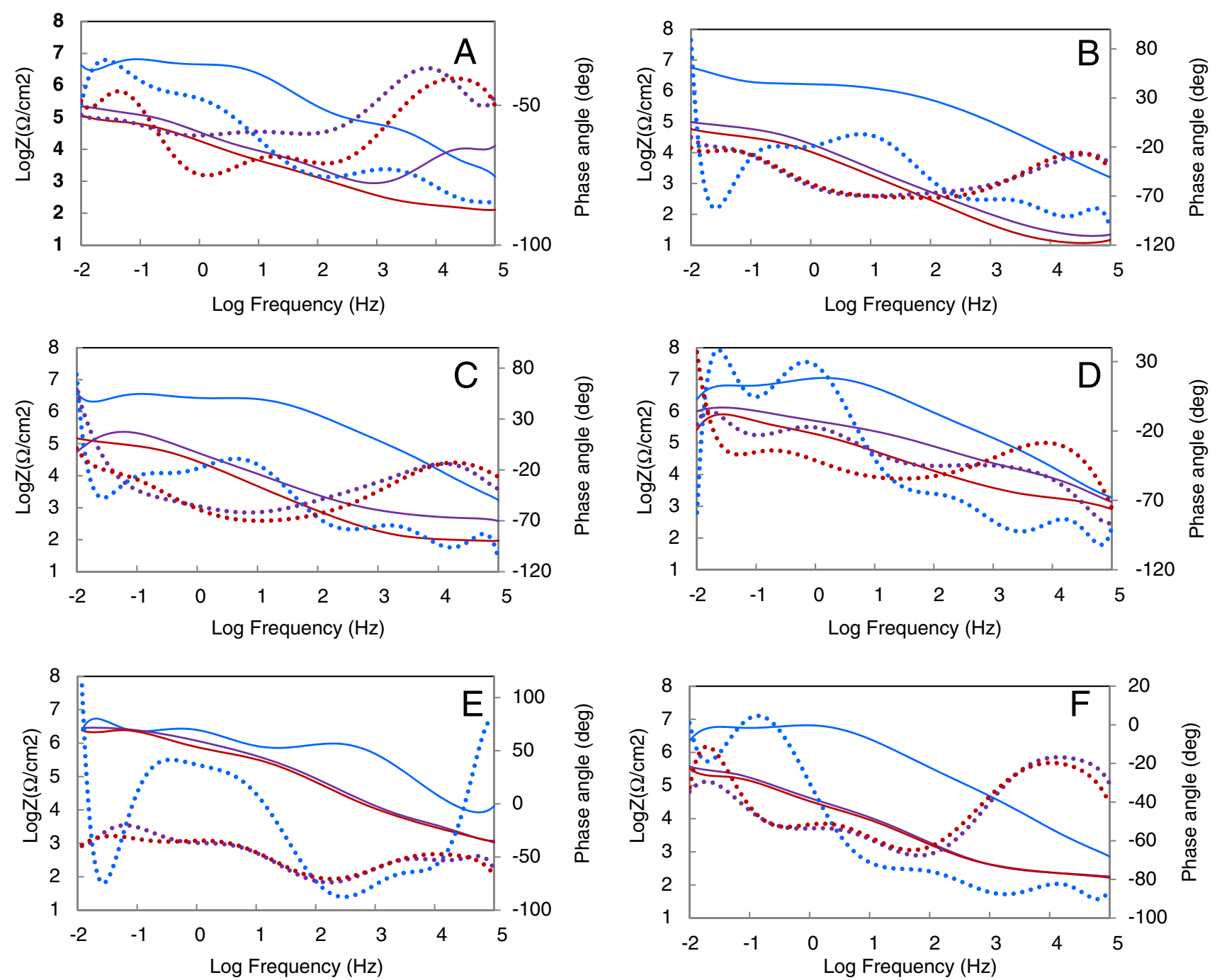

Fig. 12 Bode plots of coatings after 0 (blue curves), 96 (purple curves) and $120 \mathrm{~h}$ (red curves) of immersion in dilute Harrison's solution for materials $\mathrm{A}$ to $\mathrm{F}$

Fig. 13 Representation of the impedance at frequency $10^{-2} \mathrm{~Hz}$ for materials A to $\mathrm{F}$

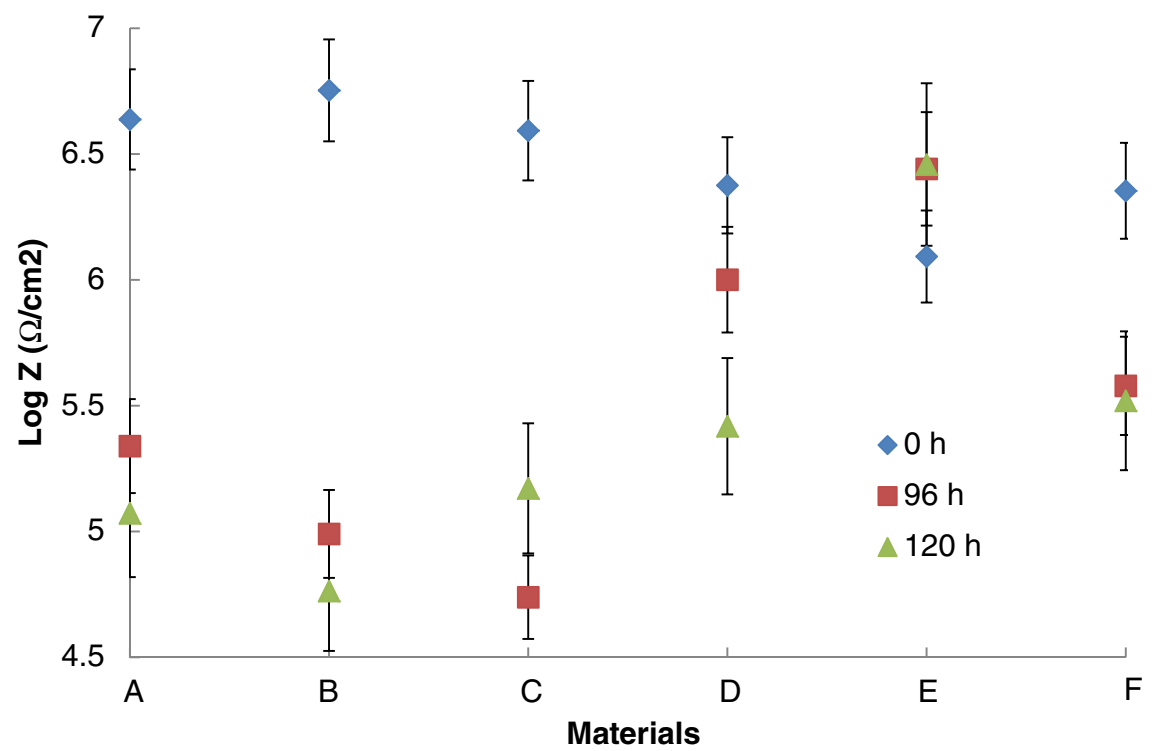


Fig. 14 Images of coatings A to

F after 24, 48 and $144 \mathrm{~h}$ NSS

exposure (color figure online)

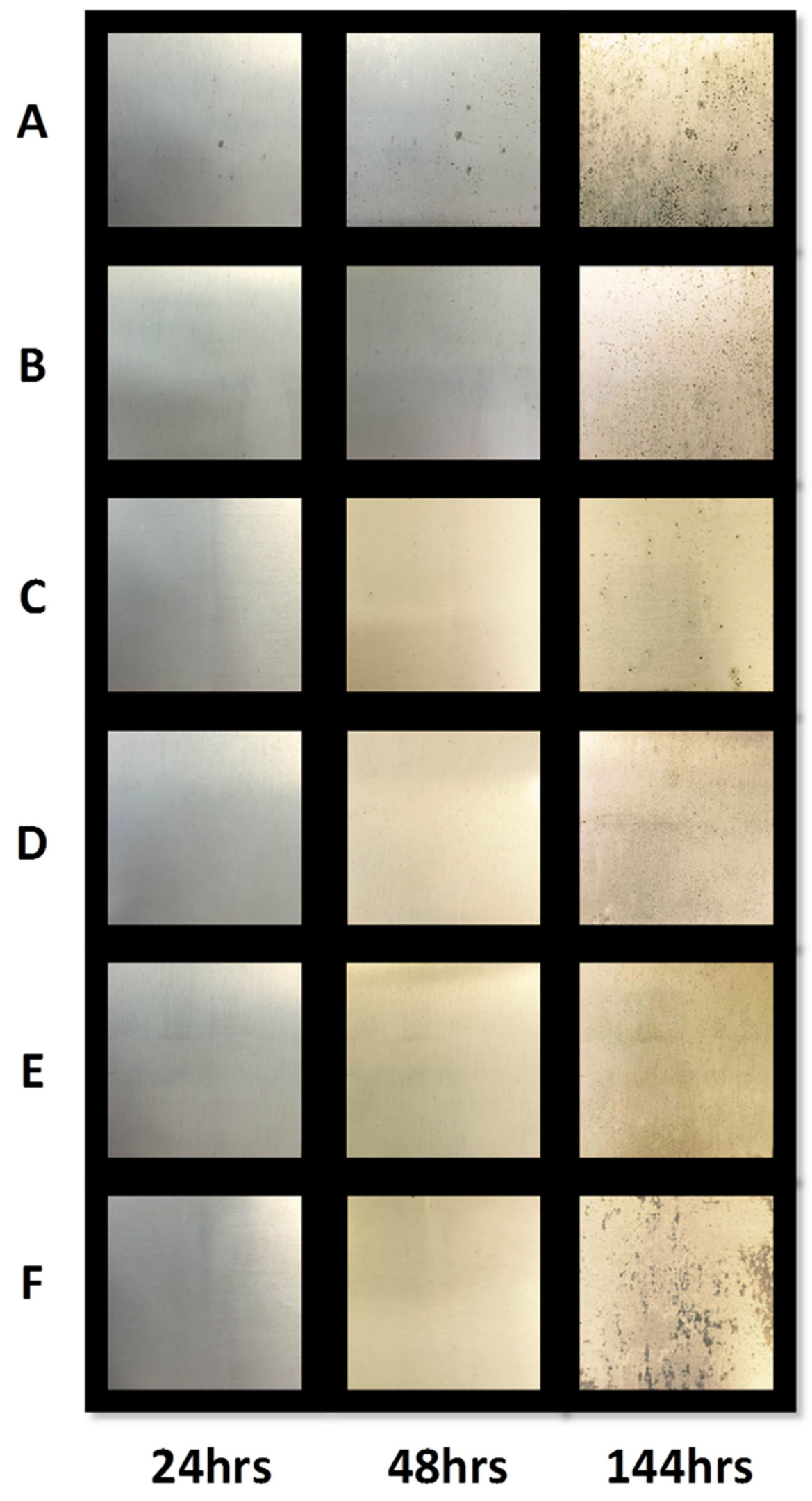


Fig. 15 Number of pits per $\mathrm{dm}^{2}$ for coatings $\mathrm{A}$ to $\mathrm{F}$ after 24 and $48 \mathrm{~h}$ NSS exposure

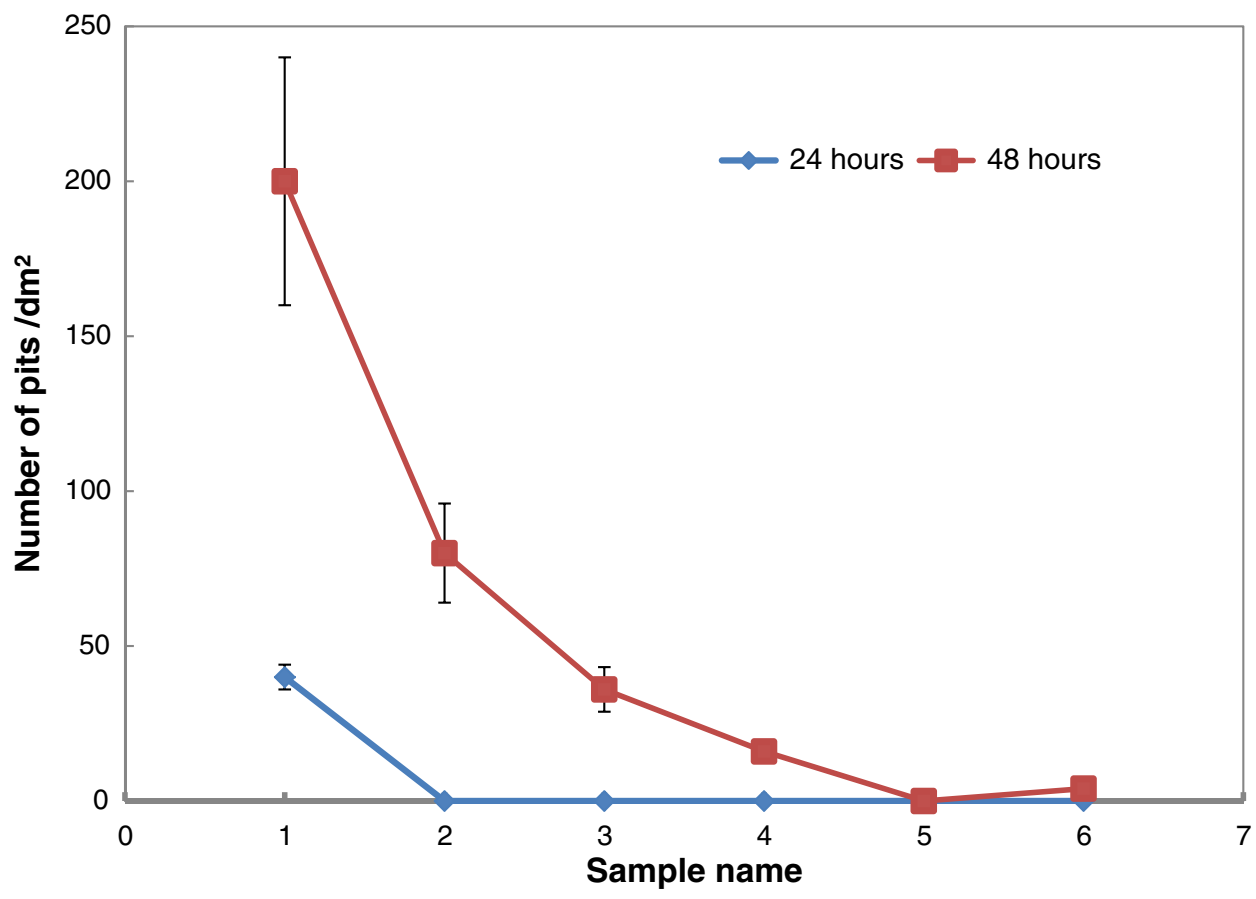

samples B, C, D showed 80, 36 and 4 pits per $\mathrm{dm}^{2}$, respectively while sample $\mathrm{E}$ remained pit-free. However, after $144 \mathrm{~h}$ of exposure it can be observed that all samples present a number of pits, exceeding 200 per $\mathrm{dm}^{2}$. It is worthy to note that the pits observed for samples D and E are punctual and smaller in size, whereas the pits for the other samples are spread across the coatings. This would suggest that the most promising candidate materials from those analysed in this work would be those containing between 20 and $30 \%$ zirconium complex concentration. In the first instance, this behaviour can be explained by the condensation of the materials that may involve either mechanical stress and/or residual porosity that would enable the penetration of corroding liquids within the coatings. The FTIR results have shown that the more condensed system was obtained with material F, while material A showed the lowest condensation degree. DLS results have highlighted a progressive increase of the particle sizes with the zirconium complex concentration, while AFM analyses revealed an increase of the surface roughness from material D. These results concord to prove that the optimum materials are those presenting a compromise between the degree of condensation and the particle size to achieve the highest level of connectivity between the nanoparticle systems, while minimising the mechanical stress and porosity.

\subsection{Coatings adhesion}

In order to ensure that the structure of the materials is the only parameter governing the anticorrosion properties of the coatings when exposed to external aggressive environments, it is essential to investigate the adhesion properties of the coatings on the AA2024-T3 substrates. This was performed by cross-cut techniques according to PN-EN ISO 2409 standard. It was found that all the coatings exhibited the same behaviour and were evaluated with at grade 0 (grades 0-5, best-worst), as shown in Fig. 16. This result is a direct proof that the adhesion cannot explain the differences in terms of anticorrosion properties and that the essential discriminatory point is the structure of the materials.

\section{Conclusion}

The focal point of this study was to determine the effect of the transition metal concentration on the morphology and anticorrosion behaviour of a hybrid silicate-based sol-gel coating deposited on AA2024-T3. The hybrid sol-gel materials have been prepared employing two hybrid precursors, an organosilane, 3-trimethoxysilylpropylmethacrylate, and a zirconium complex prepared from the chelation of zirconium $n$-propoxide and methacrylic acid, with the sol-gel then coated on AA2024-T3 substrates. The structure of the hybrid sol-gel formulation was modified by altering the concentration of the transition metal complex. The materials developed herein were characterised by DLS, FTIR, ${ }^{29} \mathrm{Si}-\mathrm{NMR}$, DSC, SEM, AFM, and the anticorrosion performances were characterised by EIS and NSS. The DLS analyses showed that there was a clear growth in the nanoparticle size in each system as the transition metal concentration increased and also that a uniform hybrid system was formed, as indicated by the single 
Fig. 16 Typical cross-cut images for coatings A to F, left (photograph image) and right (optical microscope image magnification of 2.5)
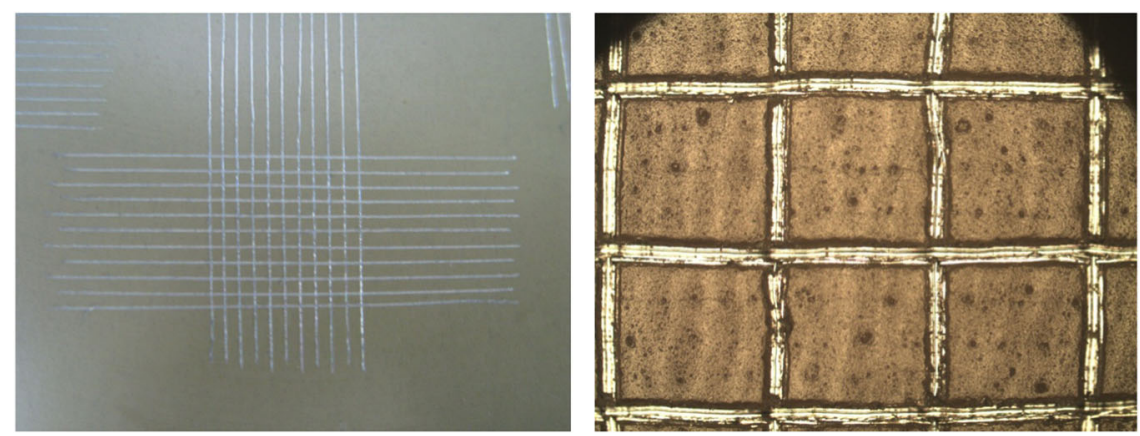

nanoparticle system recorded. To explain this phenomenon, a hypothesis concerning the role of the zirconium complex on the intra- and inter-nanoparticular reactivity was proposed. The FTIR and ${ }^{29}$ Si-NMR characterisations concord to demonstrate that the increase of the transition metal does indeed have an effect on the condensation of the materials. Interestingly, FTIR showed an increase of $\mathrm{Si}-\mathrm{O}-\mathrm{Zr}$ bonds while ${ }^{29} \mathrm{Si}-\mathrm{NMR}$ showed a predominance of low condensed silicon species ( $T_{0}$ and $T_{1}$ groups) for concentrations of zirconium complex greater than $10 \%$. This phenomenon has primarily been explained by the sterical hindrance of the zirconium atom limiting the formation of fully condensed $T_{3}$ species. NSS showed that the most corrosion resistant coatings were obtained with the materials containing a concentration of 20 and $30 \%$ of zirconium complex. To further identify the optimum formulation of the series developed here, EIS showed that the material containing $30 \%$ of zirconium complex exhibited the highest anticorrosion properties. Remarkably, this material showed a stable impedance value through the whole duration of the characterisation, fixed here at $120 \mathrm{~h}$.

In summary, this paper has highlighted the important role of the transition metal on the condensation and passive anticorrosion properties of silicate-based coatings. Further studies will include the investigation of other processing parameters such as $\mathrm{pH}$, the nature of the solvents, the hydrolysis degree, as well as employing other structural and morphological characterisation techniques, such as gas adsorption-desorption analysis. These future studies are essential in order to further understand the relationship existing between the structure, morphology and coatings' anticorrosion performances as well as strengthening efforts towards the design and development of innovative coatings for the protection of aluminium alloys and other metals.

\section{References}

1. International Agency for Research on Cancer, IARC monograph: chromium (VI) compounds. Vol 100C, 2012, 147-168
2. Varma PCR, Colreavy J, Cassidy J, Oubaha M, McDonagh C, duffy B (2010) Thin Solid Films 518:5753-5761

3. Alinejad S, Naderi R, Mahdavian M (2016) Prog Org Coat 101:142-148

4. Ramezanzadeh B, Haeri Z, Ramezanzadeh M (2016) Chem Eng J 303:511-528

5. Dimitriev Y, Ivanova Y, Iordanova R (2008) History of sol-gel science and technology. J Univ Chem Technol Metall 43 (2):181-192

6. Twite RL, Bierwagen GP (1998) Review of alternatives to chromate for corrosion protection of aluminum aerospace alloys. Prog Org Coat 33(2):91-100

7. Hench LL, West JK (1990) The sol-gel process. Chem Rev 90 (1):33-72

8. Brinker C, Scherer G (1990) Sol-gel science: the physics and chemistry of sol-gel processing. Adv Mater 3(10):912

9. Lakshmi RV, Aruna ST, Sampath S (2017) Appl Surf Sci 393:397-404

10. Balaji J, Sethuraman MG (2016) Prog Org Coat 99:463-473

11. Recloux I, Gonzalez-Garcia Y, Druart M-E, Khelifa F, Dubois P, Mol JMC, Olivier M-G (2016) Surf Coat Technol 303:352-361

12. Chrusciel JJ, Lesniak E (2015) Prog Polym Sci 41:67-121

13. Rodič P, Mertelj A, Borovšak M, Benčan A, Mihailović D, Malič B, Milošev I (2016) Surf Coat Technol 286:388-396

14. Yu F, Akid R (2016) Corrosion protection of AA2024-T3 alloy by modified hybrid titania-containing sol-gel coatings. Prog Org Coat doi:10.1016/j.porgcoat.2016.09.022

15. Suzana AF, Ferreira EA, Benedetti AV, Carvalho HWP, Santilli CV, Pulcinelli SH (2016) Surf Coat Technol 299:71-80

16. Kunst SR, Cardoso HRP, Oliveira CT, Santana JA, Sarmento VHV, Muller IL, Malfatti CF (2014) Appl Surf Sci 298:1-11

17. Vargas Harb S, Machado Cerrutti B, Helena Pulcinelli S, Valentim Santilli C, Hammer P (2015) Surf Coat Technol 275:9-16

18. Qian M, Mcintosh Soutar A, Hui Tan X, Ting Zeng X, Wijesinghe SL (2009) Thin Solid Films 517:5237-5242

19. Echeverría M, Abreu CM, Lau K, Echeverría CA (2016) Prog Org Coat 92:29-43

20. Figueira RB, Silva CJR, Pereira EV (2015) J Coat Technol Res 12 (1): $1-35$

21. Oubaha M, Smaïhi M, Etienne P, Coudray P, Moreau Y (2003) J Non-Cryst Solids 318(3):305

22. Copperwhite R, O'Sullivan M, Boothman C, Gorin A, McDonagh C, Oubaha M (2011) Microfluid Nanofluid 11(3):283

23. Elvira MR, Mazo MA, Tamayo A, Rubio F, Rubio J, Luis Oteo J (2013) J Chem Eng 7:120-131

24. Pickup DM, Mountjoy G, Wallidge GW, Newport RJ, Smith ME (1999) Phys Chem Chem Phys 1:2527

25. Varma PCR, Colreavy J, Cassidy J, Oubaha M, Duffy B, McDonagh C (2009) Prog Org Coat 66:406 
26. Weihua Z, Gaoyang Z, Zhiming C (2003) Mater Sci Eng B 99:168

27. Babonneau F, Maquet J (2000) Polyhedron 19(3):315-322

28. Hayashi E, Shimokawa T (2016) Microporous Mesoporous Mater 219:178-185
29. Baccile N, Babonneau F (2008) Microporous Mesoporous Mater 110:534-542

30. Macdonald JR (Ed) (1987) Impedance spectroscopy emphasising solid materials and systems. Wiley/Interscience, New York, NY 